\title{
Iterative Prototyping of Strategy Implementation Workshop Design
}

\author{
Kryger, Anders
}

Document Version

Accepted author manuscript

Published in:

Journal of Strategy and Management

DOI:

10.1108/JSMA-07-2017-0051

Publication date:

2018

License

Unspecified

Citation for published version (APA):

Kryger, A. (2018). Iterative Prototyping of Strategy Implementation Workshop Design. Journal of Strategy and Management, 11(2), 166-183. https://doi.org/10.1108/JSMA-07-2017-0051

Link to publication in CBS Research Portal

\section{General rights}

Copyright and moral rights for the publications made accessible in the public portal are retained by the authors and/or other copyright owners and it is a condition of accessing publications that users recognise and abide by the legal requirements associated with these rights.

\section{Take down policy}

If you believe that this document breaches copyright please contact us (research.lib@cbs.dk) providing details, and we will remove access to the work immediately and investigate your claim.

Download date: 26. Apr. 2023 


\title{
Iterative Prototyping of Strategy Implementation Workshop Design
}

\author{
Anders Kryger \\ Journal article (Accepted manuscript*)
}

\section{Please cite this article as:}

Kryger, A. (2018). Iterative Prototyping of Strategy Implementation Workshop Design. Journal of Strategy and Management, 11(2), 166-183. 001: 10.1108/JSMA-07-2017-0051

\section{DOI: 10.1108/JSMA-07-2017-0051}

This article is [C Emerald Group Publishing and permission has been granted for this version to appear here: https://research.cbs.dk/en/publications/iterative-prototyping-of-strategy-implementation-workshop-design. Emerald does not grant permission for this article to be further copied/distributed or hosted elsewhere without the express permission from Emerald Group Publishing Limited.

* This version of the article has been accepted for publication and undergone full peer review but has not been through the copyediting, typesetting, pagination and proofreading process, which may lead to differences between this version and the publisher's final version AKA Version of Record. 


\section{Iterative prototyping of strategy implementation workshop design}

Anders Kryger, Copenhagen Business School, Denmark

\section{Structured abstract}

Purpose: The purpose of this study is to demonstrate how a strategy implementation workshop design can be developed and tested while minimizing the time spent on developing the design.

Design/methodology/approach: This multiple case study at a diesel engine company shows how iterative prototyping can be used to structure the design process of a strategy implementation workshop.

Findings: Strategy implementation workshop design can be developed in resource-constrained environments through iterative prototyping of the workshop design. Each workshop iteration can generate value in its own right and at the same time the workshop design can be optimized until the final, most effective, design is found which can then be rolled out.

Research limitations/implications: In a strategy-as-practice perspective, this study shows how scholarly attention to micro-level strategy praxis at a company can be enlightening to strategy consultants who need to conduct strategy implementation workshops.

Practical implications: By selecting an iterative modular workshop design, the strategy consultant has at his/her disposal a strategy tool that is easily adaptable to organizational practice and one for which s/he can draw on his/her experience as well as add to his/her knowledge base.

Originality/value: Introducing iterative prototyping in an organizational context can facilitate fast yet structured development of a rigorous workshop design. Strategy consultants are provided with empirical examples of how an iterative prototyping process can be structured across multiple workshops.

\section{Introduction}

This paper analyzes iterations of design of strategy workshops, which are a common practice in organizations (Healey et al., 2015, p. 507). The paper answers the call to examine "how basic design features relate to workshop outcomes" (Healey et al., 2015, p. 508; see also Jarzabkowski and Spee, 2009). The practical challenge for organizations is how to develop and test a workshop design while minimizing the time spent on the development phase prior to the intervention (Coghlan and Shani, 2005, p. 534). This study presents an iterative, modular approach to workshop design where a number of workshop modules can be added and removed depending on the organizational task at hand. It offers an approach to designing strategy implementation workshops that is low risk in terms of time and resources. A series of workshop design iterations at a diesel engine company, that urgently needed complex organizational problems to be solved while ensuring that the solutions were aligned with strategy, provide the empirical setting for addressing the research question: how can strategy implementation workshop design be developed in resource-constrained environments?

At the diesel engine company, it was formerly normal practice to conduct strategy workshops with whole departments when strategy was to be implemented. Former workshop designs were thought out by strategy consultants, introduced to managers at a briefing and the managers were then expected to carry out the workshops with their employees. Reviews of the workshops and their output, however, showed that although some managers carried out the workshops as intended by the strategy consultants, some did not (at all) and some changed the concept to match their own department's needs. This study concerns a point in time where 
problem-solving and strategy alignment was urgent to top management and therefore effort was put into empirically testing the workshop design before rolling out the final design by passing it on to the managers. This study zooms in on the pre-implementation period where the strategy was developed, but had not yet been communicated to employees, where evaluations of four workshop iterations led to an optimization of the workshop design which could then be rolled out to employees when strategy implementation started immediately after. Unlike former workshop series, this workshop series was not thought into being, but spoken into being through iterative practice.

The paper is structured as follows: a literature review will show that little research has described the preimplementation phase of a strategy implementation workshop series where the workshop design is developed to match the organizational objectives. The concept of iterative prototyping will be introduced to describe a design approach that revolves around iteratively testing workshop modules in practice until an optimum design vis-à-vis the organizational objectives is reached. After a description of the method, which is a single company multiple case study conducted by an insider action researcher, the findings will describe four workshop iterations at the diesel engine company that led to the definition of the final workshop design. The findings will also describe the micro processes of the workshop modules that were tested in the four iterations to contribute to the knowledge pool of strategy practices and thus serve to inform practitioners and scholars alike. The discussion will address the contribution of iterative prototyping in workshop design, and the paper concludes that strategy implementation workshop design can be developed in resource-constrained environments through iterative prototyping.

\section{Zooming in on the pre-implementation design phase of strategy implementation workshops}

This literature review of strategy workshop studies in a design perspective will emphasize three problematic features of previous studies: first, they have focused on participants' conduct at and following the workshop as opposed to the pre-workshop phase where the workshop is planned; second, they have focused on workshops with a duration of one or more days as opposed to shorter workshops; and third, they have focused on strategy development or review as opposed to implementation. Through a focused reading of design literature, I will compare the pre-workshop design phase to iterative prototyping and further develop this concept in a strategy implementation workshop context to address the empirical gap concerning the development phase of short workshops with the objective of implementing strategy.

Strategy is a continuous evolutionary process (Pugh and Bourgeois, 2011, p. 172) that enables long-term planning of resources in a business context. In the empirical context of the diesel engine company, the strategy process was managed by the author as in-house strategy consultant. Strategy workshops are an important type of strategic episode (Hendry and Seidl, 2003) because they "provide a rare opportunity to suspend normal structures to reflect on current policies and engage in new strategic conversations" (Healey et al., 2015, p. 508). Strategic episodes are characterized by three notions: initiation where the participants decouple themselves from everyday work, conduct which deals with the activities of a particular episode, and termination where everyday work is resumed (Jarzabkowski and Seidl, 2008, p. 1395): by allowing participants to step out of everyday work, strategy workshops allow them to reflect on their normal practices, to see these practices in new contexts and to propose change. After completion of a strategy workshop, transfer of plans made at the workshop to the wider organization is important to enable strategic change (Maclntosh, MacLean and Seidl, 2010, p. 304). Participants at strategy workshops, which mostly take place over two to four days (Hodgkinson et al., 2006, p. 483), are predominantly senior managers and executives (p. 487), and the prevalent objective of a workshop is strategy development (p. 483). However, their design can be twisted and turned to match particular organizational contexts (Paroutis, Franco and Papadopoulos, 2015, p. 49). Strategy workshops are often facilitated by internal or external strategy consultants (Knott, 2008, p. 26; Gherardi and Perrotta, 2014, p. 135). 
Empirical studies of strategy workshops have focused on conduct at workshops and on the organizational effects that resulted from the workshop, respectively:

First, ten publications zoom in on conduct at the strategy workshop or meeting: two studies using LEGO bricks as tool to facilitate participants' reflection on their organization in an effort to design strategy showed that workshops involving the material co-construction, deconstruction and reconstruction of LEGO structures had a positive effect on the desired outcome to develop strategy at a telecommunications company and at four Danish companies, respectively (Roos, Victor and Statler, 2004; Bürgi, Jacobs and Roos, 2005). A study of 51 strategy meetings within three universities showed that the three micro flows - emergence, maintenance/development, and selection/de-selection - imply a stabilizing or destabilizing of strategic orientations (Jarzabkowski and Seidl, 2008). A conduct-focused study of strategy making at a business division of a multinational mechanical engineering company showed that strategy workshops can be an integral part of a company's strategy process, but that opposition to and rejection of participation at the strategy workshops can constrain strategy making (Schwarz, 2009) - although the study makes recommendations for workshop planning practice, it does not analyze pre-workshop planning, it only observes the execution of strategy workshops. Similarly, a study of discursive strategies showed that "the egalitarian leadership style increases the likelihood of achieving a durable consensus" (Wodak, Kwon and Clarke, 2011, p. 593), that five discursive strategies - re/defining, equalizing, simplifying, legitimating, and reconciling - can be used to "develop shared views around strategic issues" (Kwon, Clarke and Wodak, 2014, p. 265), and that naturally occurring talk at such a meeting can be an important venue for strategizing (Clarke, Kwon and Wodak, 2012). An ethnographic study of discourse at top team meetings identified team relational dynamics as a mechanism that links emotional dynamics and strategizing processes (Liu and Maitlis, 2014). From a quantitative perspective, a study of managerial experience at strategy workshops showed that strategy workshops are important for formal strategy emergence (Hodgkinson et al., 2006). Similarly, another quantitative study describes factors that may influence the successful execution of strategy workshops based on a survey with 639 managers, e.g. first, that workshops with the objective to resolve urgent issues are perceived less successful compared to workshops that are part of the company's normal planning cycle; second, that the duration of a workshop is not correlated with its perceived success; third, that a large number of workshop participants have a negative correlation with perceived successfulness of a strategy development workshop whereas the number of participants has no effect on the perceived successfulness of strategy implementation workshops (van Aaken, Koob, Rost, \& Seidl, 2013 who reject six other interesting hypotheses).

Second, two publications focus on conduct at the workshop as well as the outcome of the workshop: a hotel group, a defense services business, an oil services business, and a non-governmental organization all wanted to change their strategy due to recent changes in the business environment of the respective organizations (Johnson et al., 2010). The study found that theories of rituals and ritualization were useful in understanding the dynamics and outcomes of strategy workshops (see also Bourque and Johnson, 2009): first, the success of the workshops to achieve their purposes within the workshops themselves depended on the emotional energy and commitment of the participants which benefited from a clear workshop process that the authority (CEO/manager) abided by and that the participants perceived as legitimate means to achieve the workshop purpose. Second, freeing participants from hierarchical norms was found to stimulate qualified questioning and challenging which was identified as an enabler of successful workshops; it could be achieved when the authority relaxed norms and endorsed the legitimacy of the workshop process and the specialist/facilitator.

Third, two publications look at the outcome of strategy workshops: a post-workshop focused study of one-off as well as series of strategy workshops at ten UK-based organizations, showed that three notions were associated with bringing about strategic change at the respective organizations: the participants' perceived momentum at 
the workshops; an organizationally appropriate frequency - not too frequent, not too infrequent; and high seniority of participants (MacIntosh, MacLean and Seidl, 2010). Through a post-workshop focus, organizational, interpersonal and cognitive outcomes were discovered as the main effect of strategy workshops in "a large-scale field survey of over 650 workshops conducted across a range of settings" (Healey et al., 2015).

In summary, previous studies of strategy workshops share three features: First, all focus on participants' and facilitators' conduct at the workshop or the organizational effects following the workshop(s). No scholarly account has been made of how a strategy implementation workshop design was developed to meet the organizational requirements. Second, all previous studies focus on strategy workshops with a duration of one or more days. No account has been made of short workshops of 2-3 hours, although strategy meetings, presumably of a couple of hours' duration, have been studied and meeting structures that stabilized or destabilized an organization's strategic orientation were described (Jarzabkowski and Seidl, 2008). Third, all previous studies explore strategy development or strategy review. No account has been made of strategy workshops as strategic episodes in connection with strategy implementation which is the point in time where the employees are introduced to a new strategy which is a crucial strategy process step (Ranjbar, Shirazi and Blooki, 2014 see also Fig.1). A likely cause is that implementation practice is not perceived as strategy practice: "capturing the contributions of nonmanagerial staff to strategy work and the development of realized strategy does not easily lend itself to study as they are not present in the events, occasions or locations typically associated with and studied in relation to strategic work, such as senior team meetings or strategy away days" (Balogun, Best and Lê, 2015, p. 1286). This scholarly perception may have led to the absence of implementation practice in the strategy workshop research agenda, e.g. in Seidl \& Guérard (2015). With this study, I aim to contribute to research on strategy workshop practice with an implementation perspective which is currently under-represented.

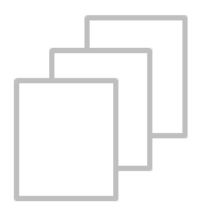

Strategy development phase

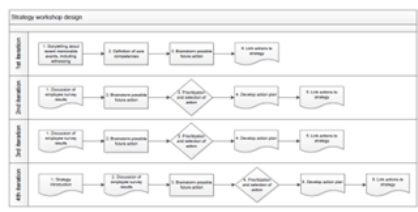

Post-development, preimplementation phase: workshop designs are empirically tested through iterative prototyping

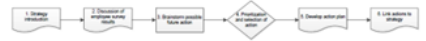

Strategy implementation phase: the final strategy implementation workshop design is rolled out to departments

Fig. 1. Iterative prototyping of strategy implementation workshop design can be done after the strategy development is finished, prior to strategy implementation in the organization.

Fig. 1 shows that first a strategy is developed and prepared to be communicated to the employees. Second, the strategy will conventionally be communicated to employees at various organizational levels through the relevant channels. However, instead of proceeding directly to communication once the strategy has been developed, I wanted to investigate if the basis for strategy implementation could be improved through iterative prototyping of workshop design in what I would label the strategy post-development, pre-implementation phase. In this phase, a small number of departments and their employees provide the testing ground for developing an optimal strategy implementation workshop design which could facilitate the actual launch of the strategy when it is formally rolled out to the entire organization. The implication of doing iterative prototyping in the strategy postdevelopment, pre-implementation phase is that, in this case study, employees of four departments were introduced to the strategy 12 days prior to all other employees, which was the time we spent on the prototype 
workshop design. At the diesel engine company, the in-house strategy consultant facilitated the iterative prototyping workshops in the strategy post-development, pre-implementation phase and then handed over the final workshop design to the department managers who then facilitated the strategy implementation workshops for their own departments in the implementation phase.

A prototyping iteration has four steps: "envisioning possibilities, creating a prototype to embody a possibility, getting feedback about the prototype, and reevaluating constraints" (Dow, Heddleston and Klemmer, 2011). The prototyping process enables developers to repeatedly "try[ing] ideas and getting feedback" (Dow, Heddleston and Klemmer, 2011). The desired result of the design process is defined through dialogue about the organizational requirements for the process combined with the practical possibilities. The possibilities consist of the strategy consultant's and the manager's experience as well as possible future experiments that have yet to be conducted. The knowledge that the strategy consultant produces while designing the contextual tool is thus "a byproduct of helping rather than a primary goal" (Schein, 2008, p. 266) and a "research implication of an experimental approach is that workshop data will vary because the workshop design is dynamic" (Welch and Piekkari, 2011, p. 744). For the strategy consultant, experience leads to mastering the technique and in addition to designing a workshop that meets the organizational objectives, they learn something from each design that they can carry into their next design (Ericsson et al., 2006).

However, time constraints and resource consumption in terms of work hours for conducting multiple prototyping iterations in organizations can lead to focus on using what is theoretically thought of as the best design as opposed to conducting empirical iterations where the design is put to the test (Austin and Devin, 2003; Schrage, 2013; Salas and Huxley, 2014). Design of a strategy implementation workshop requires time to conduct each additional iteration and because of the direct bottom-line effect of time consumption in connection with prototyping, organizations often avoid it "because they believe the cost/investment will be significant and the return will be minimal" (Dow, Heddleston and Klemmer, 2011). Additionally, it can be a challenge for strategy consultants to argue that the best workshop design can be developed through a number of sub-optimal iterations because what top manager will settle for anything sub-optimal?

The strategic decision to conduct iterations that may lead to an optimal design versus selecting a poorer, but standard, design in the face of increased expenditure is an essential question that any manager must ask him/herself. In an organization, top management may order a strategy implementation tool, but it often affects employees, not top managers per se. Ultimately, strategy implementation tools are means to achieve certain desired ends, but the process of achieving those ends often involve the employees rather than top managers. Therefore, organizational prototyping can be said to be sponsored by top management for the benefit of the employees who will, if the iterations are successful, experience a better strategy process. That effect can be translated into a more effective strategy tool. The remainder of this paper reports on the iterative prototyping of a strategy workshop design where added resource consumption in the form of multiple iterations to achieve an optimal strategy implementation workshop design was consciously selected by top managers. Each design iteration should add value in its own right while the iterations as a whole should maximize the effect of the strategy workshop before the workshop design was fixed and serialized at subsequent workshops.

In summary, I suggest that studying the development process of strategy workshops that aim at implementing strategy, prior to the actual strategy launch, can further the strategy as practice research agenda while being practically informative to strategy consultants. With this study, I propose the concept of iterative prototyping as method to design a strategy workshop that matches a particular organization for the benefit of employees as well as managers.

\section{Method}


Developing robust, actionable knowledge about the process of change while changing the organization is not only a distinctive characteristic in action research (Coghlan, 2011), it supports the strategy as practice field's research objective to enhance strategy praxis and practice and develop highly skilled practitioners (Whittington, 2006, p. 629). Action research is in its widest sense a partnership between a researcher and one or more practitioners that seeks to create actionable knowledge in order to learn from it and disseminate the learning (Huang, 2010). The research and practitioner roles can, however, be centered in the same person: the insider action researcher, who conducts research inside the organization where s/he is permanently employed (Roth, Sandberg and Svensson, 2011). An insider action researcher needs to manage the contrast between the roles as organizational member and researcher to generate actionable knowledge (Coghlan, 2011, p. 71). An insider action researcher's proximity to organizational processes and the possibility to stand back and reflect, learn and disseminate give him/her an ideal position to generate strategically necessary know-how (Coghlan and Shani, 2008) that can further develop strategy praxis, practice and practitioners.

In this multiple-case study, top management at a diesel engine company decided to conduct a series of strategy workshops with participation of a department manager and his/her employees to implement strategy (Ranjbar, Shirazi and Blooki, 2014). The term 'workshop series' does not refer to a sequential number of workshops with the same participants where a common understanding is developed over time (e.g. as reported by Schwarz, 2009), but to a fixed workshop design that is applied in different departments with the same purpose. The company was unaccustomed to working with strategy because it had been highly successful within its product niche, a particular type of marine diesel engines, for two decades. As a reaction to the global financial crisis in the late 00's and its delayed effects in international shipbuilding and trade, the company needed a strategy, but the organization was challenged because staff at various levels had worked very little with strategy in the past decades. Top management therefore decided that the organization needed strategic sensitization to facilitate the implementation of the new top-down strategy. The sensitization should ensure alignment of action planning and execution with the new strategy (Macpherson and Antonacopoulou, 2013, pp. 267-268). The actions that needed planning were solutions to organizational problems that the departments faced that had been building up in a kind of stasis during the successful years. This bottom-up sensitization measure should complement the topdown strategy that was being cascaded down the hierarchy through other channels - however, only the strategy workshops are in focus in this paper.

Four department managers of engineering design and operation, respectively, volunteered for iterative prototyping of the emerging workshop design - in fact the workshop design process was not that different from the engine component design process they were used to. The first four managers and their employees gave me feedback that I used to modify the workshop design to a point where it effectively solved organizational problems while at the same time ensured that the action planning of solutions was aligned with the strategy. The workshop design tested in the fourth and final workshop iteration would continue to be used unaltered for the remainder of the workshop series at the company, currently comprising more than 25 workshops in 2016 and more than double that planned in 2017. The challenge of conducting sub-optimal workshops, four in this case, until the final design was found was dealt with through framing of the study as a project that would ultimately benefit and be tailored to the organization. In the case of the diesel company, the managers agreed to this premise and were enthusiastic about being part of a structured development process of something non-product related, which was not normal practice at the company.

The frequency of and time between the workshops were planned according to the departments' production schedule, and the department managers selected a date and time when most employees could participate in the workshops. The four workshop design iterations were conducted in 2016 on 7 September, 8 September, 14 September, and 15 September, respectively; the first, second, and fourth with engineering design departments 
and the third with an engineering operation department. Sound recordings were made at the workshops, and although they were not part of the decision making or design process which rested solely on evaluation by the managers, participants and me as facilitator of the workshops, they enabled transcription of the workshops (in NVivo, totaling 155 pages), which were later analyzed and are summarized in the Findings section below to demonstrate the micro processes at some of the workshop modules.

The strategy workshop design consisted of several workshop module combinations. The modules were introduced based on empirical research on strategy, notably interview technique from narrative therapy which had been used successfully at previous workshops at the company (AUTHOR). The strategy workshop design was changed through small-scale increments (Bamford and Forrester, 2003, p. 557) from workshop to workshop to study the effect of the workshop design changes and to integrate feedback in the next iteration. Fig. 2 shows how the strategy workshop design was modularized and changed according to the requirements of the respective departments in a process where the four workshops are viewed as part of the same development process. At the end of each workshop, the employees evaluated the workshop, and after the workshop, the results were evaluated by the manager and the strategy consultant, who also presented the results to colleagues at the company and to academic peers. Based on this evaluation, the planning of the next workshop with a new department would commence. Particularly the sequence of four consecutive workshops, analyzed as a whole and together making up the iterative prototyping process as well as its problem-orientation distinguishes this study from previous studies on organization development, e.g. Stavros et al. (2003 on appreciative inquiry).

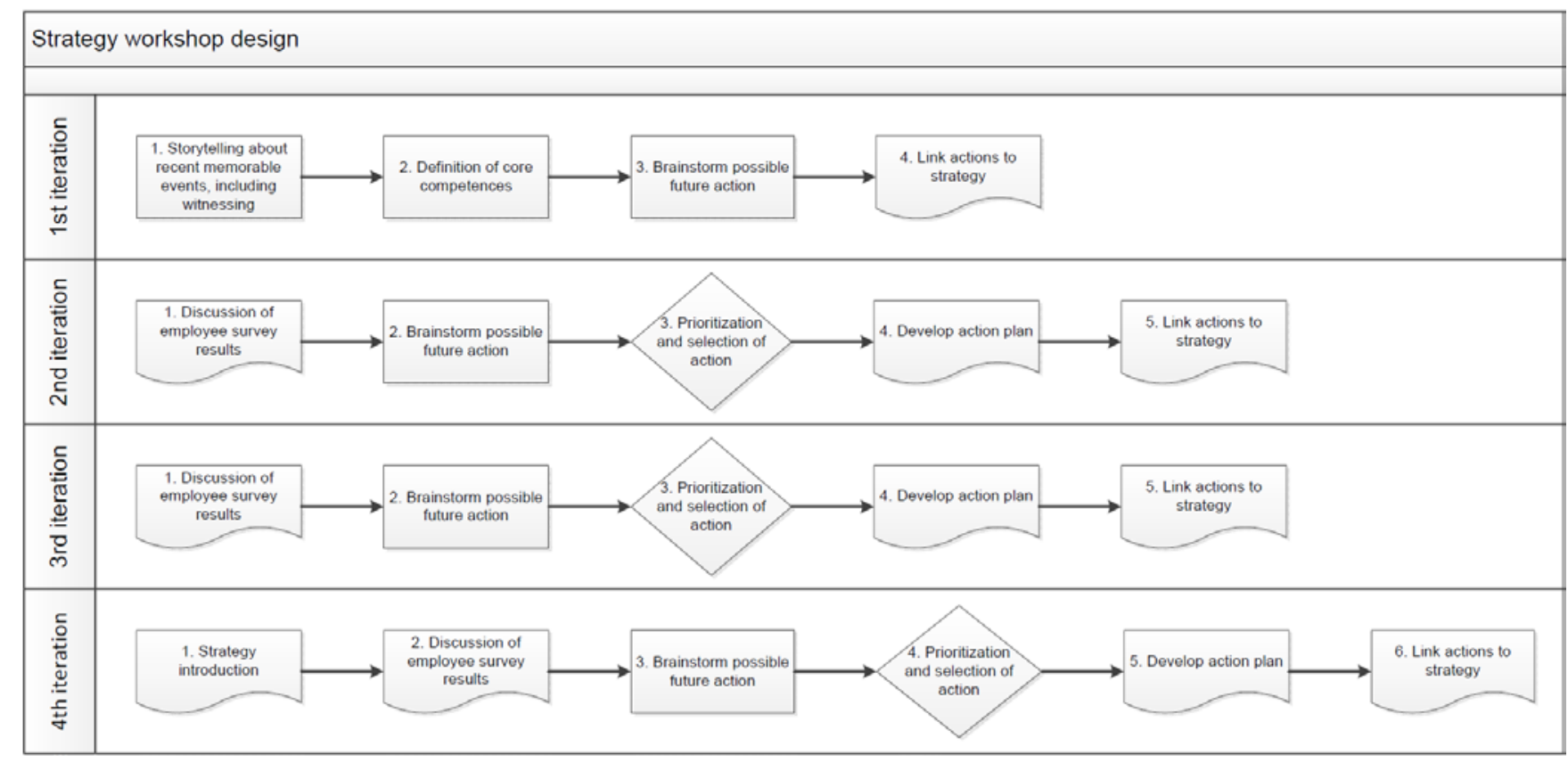

Figure 2. Prototyping iterations of the strategy implementation workshop design. All workshops had a duration of 150-180 minutes and five or six participants. The composition of modules changed from iteration to iteration except from iterations 3 to 4 where the type of department changed instead of the module composition.

\section{Main findings}

The findings pertain to different levels of analysis: first, an account of the modular development of the workshop design across four workshop iterations is described in Table 1, which shows the change log. Second, the micro 
processes in each workshop module are described based on notes and transcriptions from the workshops. The term micro process indicates that the processes that are analyzed in this paper consist of sentences and stories uttered by the participants individually and collectively in the workshops as opposed to process studies which target analysis of longitudinal organizational processes (Langley et al., 2013).

\begin{tabular}{|c|c|c|c|}
\hline Iteration & Department & Development target of iteration & Findings in iteration \\
\hline 1 & $\begin{array}{l}\text { Engineering } \\
\text { Design } 1\end{array}$ & $\begin{array}{l}\text { 1. Can free storytelling of recent } \\
\text { memorable events, be they positively } \\
\text { or negatively perceived by the } \\
\text { participants, build a foundation for a } \\
\text { qualified discussion of shared problems } \\
\text { and strengths in the department? } \\
\text { 2. Can participants define their shared } \\
\text { core competences? } \\
\text { 3. Will a definition of shared core } \\
\text { competences facilitate a brainstorm of } \\
\text { possible future actions that seek to } \\
\text { solve perceived problems or amplify } \\
\text { perceived strengths? } \\
\text { 4. Can the actions be linked to strategy? }\end{array}$ & $\begin{array}{l}\text { 1. No free storytelling leads to a lack of focus in } \\
\text { the workshop } \\
\text { 2. Not effectively: it was a time-consuming } \\
\text { activity where the participants read notes } \\
\text { from each story told by a colleague and } \\
\text { underlined words or structures perceived as } \\
\text { a core competence } \\
\text { 3. Attention was given to amplifying the } \\
\text { perceived shared strengths rather than } \\
\text { solving the identified problems } \\
\text { 4. Yes the actions were linked to strategy }\end{array}$ \\
\hline 2 & $\begin{array}{l}\text { Engineering } \\
\text { Design } 2\end{array}$ & $\begin{array}{l}\text { 5. Can a theme by theme or question by } \\
\text { question discussion of the employee } \\
\text { survey results for the particular } \\
\text { department facilitate a structured, } \\
\text { shared definition of the department's } \\
\text { problems? } \\
\text { 6. Is the brainstorm of possible future } \\
\text { actions more problem-oriented and } \\
\text { focused compared to the previous } \\
\text { iteration? } \\
\text { 7. Does it make sense for the participants } \\
\text { to prioritize the possible actions } \\
\text { according to implementation complexity } \\
\text { as one dimension and impact on } \\
\text { strategy as the other? } \\
\text { 8. Does the prioritization facilitate easy } \\
\text { selection of action(s) for } \\
\text { implementation? } \\
\text { 9an an action plan be developed? } \\
\text { 10. Can the link to strategy be confirmed? }\end{array}$ & $\begin{array}{l}\text { 5. Yes without difficulty } \\
\text { 6. Yes actions were defined to each identified } \\
\text { shared problem } \\
\text { 7. Yes it was easy for the participants to } \\
\text { evaluate implementation complexity and the } \\
\text { relative impact on strategy for each action } \\
\text { their defined in the brainstorm } \\
\text { 8. Yes when it was time to select one or more } \\
\text { actions to be implemented, each action had } \\
\text { been discussed in detail including } \\
\text { implementation complexity and expected } \\
\text { impact on strategy so agreement on } \\
\text { selection was reached } \\
\text { 9. Yes the action plan was collectively defined } \\
\text { and agency was exercised to undertake the } \\
\text { selected action } \\
\text { 10. Yes the link to strategy was confirmed }\end{array}$ \\
\hline 3 & $\begin{array}{l}\text { Engineering } \\
\text { Operation } 1\end{array}$ & $\begin{array}{l}\text { 11. Can the workshop design from the } \\
\text { previous iteration be validated as an } \\
\text { effective design? }\end{array}$ & $\begin{array}{l}\text { 11. No the strategy needs to be introduced up } \\
\text { front; according to participants, this will } \\
\text { facilitate their prioritization and selection of } \\
\text { action as well as facilitate the confirmation of } \\
\text { the link between action and strategy. Too } \\
\text { much time was spent trying to understand } \\
\text { the strategy in the middle of the workshop } \\
\text { thus pausing the workshop flow }\end{array}$ \\
\hline 4 & $\begin{array}{l}\text { Engineering } \\
\text { Design } 3\end{array}$ & $\begin{array}{l}\text { 12. Does the introduction of the strategy as } \\
\text { the first workshop module improve the } \\
\text { workshop flow compared to the } \\
\text { previous iteration? } \\
\text { 13. Can the workshop design be validated } \\
\text { as an effective design? }\end{array}$ & $\begin{array}{l}\text { 12. Yes framing the workshop with strategy } \\
\text { provides an effective frame for steering the } \\
\text { dialogue } \\
\text { 13. Yes this design is perceived as logical and } \\
\text { effective in identifying problems and } \\
\text { solutions and aligning them with a strategy }\end{array}$ \\
\hline
\end{tabular}

Table 1. Development targets of the workshop iterations

Table 1 shows that the development of the strategy workshop design continues through four workshop iterations and each iteration can be seen as a test of the design changes from the previous workshop. In addition to a 
short evaluation by the participants at the end of each of the first two workshops, the iterations were evaluated shortly after their termination by the respective department manager and the author as strategy consultant. The third iteration was a replication of the second iteration, but whereas the second iteration was done for an engineering design department, the third iteration was done with an engineering operation department, the difference being one of employee specialization: design engineers are predominantly highly specialized in designing a few selected components of a diesel engine, and work at their desks at the office, whereas engineering operation engineers are mostly travelling and have hands-on contact with the products to ensure their operation onboard ships. The third iteration would thus work as a control of the workshop design in a different demographic context. Prior to the fourth iteration, the strategy consultant had discussed when would be an appropriate time to introduce the strategy with academic peers, and had arrived at the conclusion that this should be done at the very first workshop module. The rationale was that the strategy would frame the entire workshop, and it would facilitate the employees' prioritization of possible future actions according to impact on strategy - because they would already be familiar with it - as well as facilitating the re-evaluation of the actions' link to strategy in the final workshop module. In evaluation of the fourth iteration with the department manager and later with academic peers, this design was judged to be the optimal design to solve problem and align solutions/actions with the strategy.

The micro process of each workshop module will now be elaborated to show how the modules worked at the workshops.

Module: storytelling about recent memorable events, including witnessing. The inquiry process followed position maps 1 or 2 in narrative therapeutic practice (White, 2007), which are focused on eliciting stories about recent events. An employee freely chooses a recent event that s/he can remember and somehow feels strongly about. Often the mere selection of the event indicates that the event is somehow important to the employee. The interview facilitates the employee's reflection on why the event seems important. In this empirical context, the purpose of the module was to address implicit knowledge about what the employees perceive as important to their job, something they hold high and strive for. The module process consists of a series of questions that seamlessly enable the employee(s) to formulate and name what they find to be important. The next step is to extrapolate the issues the employees identify as being important and conduct strategic action planning that capitalizes on these important issues. In narrative practice, witnessing can amplify the issues that a person identifies as being important. Witnessing practice involves a group of people listening for particular cues during the inquiry process and engaging in a joint debriefing after the person has finished his/her story. At the strategy workshops, the witnesses were the colleagues of the person interviewed.

The following example from a workshop shows the storytelling process in a narrative therapy interview:

- AK: [...] try to give me a concrete example from your work on the [prototype of engine type] project of something you made where, looking back, you needed more time?

- Henning: yeah for example we didn't make sure that the drillings were placed correctly, some measures weren't included in the drawings, a drain valve was missing, it wasn't verified if some areas were large enough - all this resulted in trouble later on where we had to compensate for some things [...] that may have been avoided if we had had more time to sit and think things through and perhaps spoken with some colleagues in the production who could have spotted the errors and evaluated if it would be a problem. But it is such a funny factor because when do you have time enough? When is it enough or when have you reached a satisfactory result?

- AK: what is your take on it - when have you reached a satisfactory result? 
- Henning: [laughs] when it works the first time but it's probably utopian to think we can deliver a $100 \%$ product the first time every time, but I think the usual obvious things should be checked [...]

- AK: so when a mail ticks in and says that something doesn't work as intended [...] what do you think?

- Henning: first I think bummer and then you check the errors [...]

- AK: so when the mail ticks in and you think bummer - what would you have preferred instead?

- Henning: I'd like to have avoided the email coming in at all. It hits you on the pride [...]

- $\mathrm{AK}$ : so this pride, does it come when the engine works the first time?

- Henning: I don't know, but there are some errors you can't prevent but then there are just stupid mistakes that result from not checking properly and they're annoying [...]

- AK: right, so when they're annoying, what's important to you in your work - what would you like to achieve?

- Henning: l'd like to make a good product and give it a good quality [...]

The problem was unfolded in details that are not included in this excerpt. The retrospective problem-orientation of this narrative interview differs from the prospective positive orientation of appreciative inquiry, i.e. the 4-D cycle: discovery, dream, design, destiny (Stavros, Cooperrider and Kelley, 2003), another organization development approach. Henning's interview was followed by witnessing where I turned to the colleagues who had been taking notes during Henning's interview and asked:

- AK: what did you particularly notice that Henning said?

- William: [...] we probably didn't work very efficiently in this case [...] we may deliver the drawings on time, but you might not feel you can vouch for the quality [...] and we want to get it right the first time [...]

- Lucas: I also wrote down quality [Louise: and time pressure] and professional pride

- AK: and what do you think is important to Henning?

- Louise: planning

- Lucas: I also noticed that our errors affect a lot of people so it's not only us that are ineffective, but all of a sudden a lot of people become involved in a small error that could have been avoided if you had had the time to correct it right

- AK: can you recognize anything Henning said in your own work lives? [...]

- Noah: yeah that time matters and that quality depends on time. It feels like all our time is spent modelling and designing and it almost feels like we need to steal time to have the design validated by colleagues in other departments [...]

- AK: ok and where did it take you to hear Henning's story - or do you maybe feel like doing something?

- William [department manager]: to me it is of course important that I try to make time for these projects or the components for the employees right and try to ensure that the right conditions are there for them to do the tasks

Interviewing strategies such as naming abstract entities, providing examples, specification, and checking for resonance and associated issues are foundational for narrative interviewing (White and Epston, 1990). They provided a structure to the storytelling module that allowed the participants to associate freely, but within a particular frame imposed by the workshop and module design. The effect on the conversation can best be described as lingering (Shapiro and Ross, 2002, p. 99), and it created a relaxed atmosphere, conducive for coauthoring problems and solutions that can "grow in importance and power" (Shapiro and Ross, 2002, p. 99).

A module based on storytelling about recent memorable events followed by witnessing can generate joint identity creation for a group of employees. The stories are selected by the participants in an unstructured manner and therefore may lack joint focus. The resonance and transport that the witnessing revolves around is 
time consuming and if the resonance and transport from teller to listeners is required in the workshop setting, much time should be spent exploring both story and witnessing. This module is at odds with problem-solving which is very much about zooming in on a particular problem which "recent memorable events" are not.

Module: definition of core competences. Building on the notes from the storytelling module, the participants' core competences can be elicited. Core competences were simply defined as 'what we do well in this department'. Here is an example from a workshop showing the top five core competences that the participants identified in the notes from the storytelling module along with their respective word count, i.e. how many times the same word was underlined.

- Core competences: Responsibility for [engine] component (12), From idea to finished component (12), Cooperation (11), Design (safe, high quality; 9), Troubleshooting (8)

However, introducing and asking participants to work with a concept such as core competence can be challenging, here expressed by one of the participants: "it was difficult to get a feeling for these core competences - at least no feelings jumped on me when I read them [after summarizing them]. I mean I barely had time to underline any words because I didn't have [time to think about what they really meant to me]". Therefore, this module needs a thorough introduction of the concept of a core competence and much time should be given to thinking about, and identifying, core competences for it to work properly in a workshop context.

Module: discussion of employee survey results. The purpose of this module is to present and jointly evaluate employee survey results for the respective department and identify the participants' frustrations through an inquiry process following position map 1 in narrative therapy (White, 2007) with the purpose to externalize frustrations through four steps: 1) negotiation of an experience-near definition of a frustration, 2) mapping the effects of the frustration, 3) evaluation of the effects, 4) justification of the evaluation - similar to the storytelling module, except without the time-consuming witnessing element, but instead focusing on achieving a rich, joint description of the frustrations.

Module: brainstorm possible future actions. The purpose of the module is to jointly generate ideas for actions that will minimize a frustration or maximize a core competence. Transcripts showed that problems (p) were followed by possible corresponding solutions (s) in random patterns:

- $\quad p_{1}-p_{n}-s_{1}-s_{n}$ (first all problems were elicited, then all corresponding solutions were elicited)

- $\mathrm{p}_{1}-\mathrm{s}_{1}-\mathrm{p}_{\mathrm{n}}-\mathrm{s}_{\mathrm{n}}$ (elicitation of a problem was followed by elicitation of a corresponding solution)

- $p_{1}-p_{2}-s_{1}-p_{3}-s_{2}-p_{4}-s_{4}$ (random pattern were solutions to not all problems were found)

The facilitator needs to be flexible and open to the various patterns of problem identification and solution brainstorm and to the fact that a possible and valuable solution to a problem may occur an hour after the problem was initially identified and during a different workshop module. As in the storytelling module, lingering at the formulation of problems and solutions as opposed to progressing quickly resulted in optimal workshop dynamics. The participants' detailed co-authoring of problems and corresponding solutions facilitated prioritization, selection and planning of action at later stages of the workshops because the participants had reached a common understanding of what the problem entailed and what an appropriate solution could be.

Module: prioritization and selection of action. The purpose of this module is to prioritize just-formulated possible future actions according to their impact on strategy on a 10-point scale spanning small to big impact, and implementation complexity similarly on a 10-point scale spanning low to high complexity. The prioritization 
leads to the participants selecting one or a number of actions. Prioritization and selection of actions, which is a challenging strategic practice (Salas and Huxley, 2014, p. 111), were facilitated by being framed by the strategy in the first workshop module in the final workshop design. The prioritization according to relative implementation complexity and relative impact on strategy worked well in allowing the participants to gain an overview of their possibilities for action. A thorough discussion of the relativity of the actions catered for participants' qualified decision-making and their exercising of agency: the more they understood the implications of the possible actions and the work they had to undertake to realize the action, the more they exercised agency for the actions that were ultimately selected. The example below shows how the participants supplemented each other in arriving at the final prioritization.

- AK: now we are going to prioritize [the actions found in the brainstorm] - [first action] is that easy or difficult to implement?

- Valdemar: it's easy to make the decision right [and thereby the action is easy to implement]?

- AK: impact on strategy - small or big? [...]

- Sebastian: there's that modularization [...]

- August: could support design methodology

- AK: so up here somewhere [pointing to the workshop poster's prioritization matrix]?

- August: yeah

- AK: [second action] - easy or difficult to implement?

- Valdemar: it's more difficult than it's easy

- August: it takes time at least

- Valdemar: I think it should be more to the right

- AK: impact on strategy - big impact?

- Theodor: I don't think it has that big impact on strategy?

- AK: so down here somewhere?

- Theodor: yeah that's probably more realistic [...]

After the prioritization, actions were selected by the participants.

Module: develop action plan. The purpose of this module was to formulate an action plan for each selected action consisting of action name, desired effect, how and when to evaluate, owner, deadline - a routine task for the participants.

Module: strategy introduction. The purpose of this module was to introduce the diesel engine company's new strategy to the participants at the workshop. This introduction was made by the facilitator with one exception where the department manager presented the strategy. 12 bullet points together making up a strategy one-pager were elaborated and the participants' questions were answered.

Module: link actions to strategy. The purpose of this module is to ensure that the actions that are formulated in the brainstorm module and later prioritized and selected are in fact linked to strategy, which was one of the overall objectives of doing the strategy implementation workshops. Linking actions to strategy was easier for the participants if they were given a thorough introduction, not only conceptually, but word by word, to the strategy at the beginning of the workshop. Introducing the strategy became a frame for the workshop which facilitated the later brainstorm on possible future actions and allowed the participants to evaluate on a qualified basis the impact of a possible action on the strategy. An example from a workshop: 
- AK: l'd like you to look at this strategy poster and figure out [reference to the department's selected action] how does it support the strategy?

- Bertram: well it's supposed to improve the competitiveness which means lower first cost of our components and ensure that the [specific component] isn't too big [...] and that it has a good fit in the ship hull

- August: [it supports] design quality methodology

- Theodor: yeah it fits right in there

- August: it could also be intensify interaction and integration with [particular customer group]

- Sebastian: I suppose you also get more satisfied employees [...]

- August: I see it more like the people who are going to do this can learn something from it [so it's indirectly something about improving employees' skills]

In summary of the main findings, a workshop design was developed through four workshop iterations, each iteration building on the learning from the previous one. Further, the evolving workshop design led to identifiable modular dynamics which were exemplified through examples from the transcripts. The findings are suggestive to strategy consultants wishing to develop a workshop design that is rigorous yet versatile.

\section{Discussion and conclusion}

Strategy implementation workshop design can be developed in resource-constrained environments through iterative prototyping of the workshop design. Executing empirical iterations of a prototype workshop design and viewing the iterations as interconnected and part of the same development process result in an optimal workshop design that is tailored to the empirical context. The intra- and inter-dynamics of various workshop modules can be tested and evaluated by employees, the department manager and the strategy consultant in each and across iterations to optimize the workshop flow. By selecting an iterative modular workshop design that is developed through iterations, the strategy consultant has at his/her disposal a strategy tool that is easily adaptable to organizational practice and one for which s/he can draw on his/her experience as well as gain and add new knowledge: by performing workshop iterations, the strategy consultant adds to his/her knowledge base in an iterative learning process while improving the strategy implementation in the organization. Although difficulties may be foreseen persuading top management to allow iterations of a workshop design to achieve the optimal modular composition of the workshop, this study at a diesel engine company suggests that the time devoted to iterations is well spent.

With this study, I assert that it can be valuable for strategy consultants to engage in an iterative prototyping process when developing strategy tools such as workshops. Ultimately, the organizational design process may be spoken into being between managers and a strategy consultant, but it is the employees who can benefit from the prototyping process to begin with because they will experience a workshop process that is designed for them - and only later, once the execution of the actions defined at the workshops shows the first results, can top management harvest the benefits of the added expenditure, in terms of time consumption, of conducting prototyping. Each iteration in the design phase can generate value in its own right and at the same time the workshop design can be optimized through each iteration. This way, developing strategy tools through iterative prototyping becomes a way to maximize the effect of the tool in a way that emulates the employees' work style and allows for their preferences and the organizational dynamics to guide the design.

This study contributes to strategy-as-practice and workshop literature by providing an empirical approach to strategy implementation praxis (Balogun, Best and Lê, 2015). First, it adds empirical knowledge of how iterative prototyping as a design feature is related to workshop outcomes (Jarzabkowski and Spee, 2009; Healey et al., 2015). Although iterative prototyping of a workshop design blurs the distinction between strategy development 
(which is what happens when analyses are interpreted, long-term resource planning is made, and the strategy package is formulated and prepared for communication) and strategy implementation (which is what happens when the strategy is communicated to the employees and key performance indicators are planned accordingly), it may only affect a small number of departments and their employees who will function as test subjects in a pursuit of the optimal workshop design. The tradeoff of doing iterative prototyping at the junction in time where the strategy is finished and just before it is implemented concerns giving these few department a sub-optimal workshop. It may be suboptimal because it lacks a rigorous step by step protocol and because it requires time and commitment from these employees (Coghlan and Shani, 2005). This study suggests that the payoff comes in terms of an empirically tested, rigorous workshop design as opposed to a theoretical workshop design that has not been empirically tested, which was the case with prior strategy implementations at the diesel engine company. Additionally, time consumption is kept at a minimum through fast iterations where prototype modules are removed and new modules added based on the empirical development.

Another contribution to strategy workshop literature that this study makes concerns the structure of workshops as strategic episodes, which consists of initiation, conduct, and termination (Jarzabkowski and Seidl, 2008): the iterative prototyping process at the diesel engine company showed that the optimal strategy implementation workshop design is initiated and terminated by strategy, or in other words, the workshop should be opened and closed by strategy. Initiation came in the form of a detailed strategy introduction; termination came when the actions that were selected (Jarzabkowski and Seidl, 2008) at the workshop were linked to the strategy. This way, the new strategy became the frame of the entire workshop, as Oscar the department manager stated in one of the workshops: "it was a good thing you presented [the strategy] at the beginning otherwise we would have just found some targets independently from the strategy and then afterwards made it fit with the strategy, but the idea is that the strategy affects our choice - that's the whole point of the strategy". Charles, an employee in the department, stated the effect of having an introduction to the strategy at the beginning of the workshop and then linking the actions to strategy at the end of the workshop: "if I should figurative language, it's sort of like the [four strategic focus areas] are these balloons that are high up in the air so we can't reach them, but we've gotten to a point where you can pull them down [...] I can make more sense of [the strategy] [...] I can look at this [strategy] and pinpoint some places and then say 'this is where we've worked [to support the strategy]"'. With regard to the third structure in a strategic episode, conduct, this study shows that narrative facilitation can support a brainstorm of actions that support the strategy. By co-authoring plans for action (Boje, 2001), employees jointly enable strategic change (Maclntosh, MacLean and Seidl, 2010).

Across all workshop modules, one basic facilitation principle generated a successful workshop that effectively solved problems as well as ensured that the resulting actions were aligned with the strategy: lingering (Shapiro and Ross, 2002, p. 99), i.e. taking time as opposed to pressing on. The more specifically the strategy was explained, the more specifically the problems and their possible solutions were described, the more detailed the prioritization and selection of actions and the action planning was, the more explicitly and clearly was the link between action and strategy described by the participants - thus leading to an effective workshop compared to the objectives of problem solving and strategy alignment of solutions. Lingering and allowing time for reflection was achieved by using facilitation technique from narrative therapy, a practice which has specificity and nuanced, contextual understanding of problems and their solutions at its very core (White, 2007). Narrative facilitation technique was an integral part of the module concerning problem identification, which in this case was related to the employee survey, and the module concerning possible future actions. Therefore, while this study shows that development of the workshop design based on iterative prototyping led to a robust design, it cannot be separated from narrative facilitation, and I invite further praxis-oriented research of iterative prototyping without narrative facilitation of the workshops to further study the organizational effects of using iterative prototyping in an organizational development process. 
When strategy consultants receive a new brief by a client, they draw on their experience in designing the process to meet the objective stated in the brief. Achieving the objective involves design features, tools and techniques already known to the strategy consultant, but may also, depending on the task at hand, involve new, unknown design elements. While developing new possible designs, knowledge about the inter- and intradynamics of the design elements is essential to the strategy consultant. The in-/exclusion of a workshop module leads to different workshop dynamics as demonstrated in the findings above. This study emphasizes the importance of the qualifications and experience of the strategy consultant in designing a successful strategy tool and it supports the strategy-as-practice agenda of developing qualified practitioners (Whittington, 2003) by contributing relative importance to strategy praxis such as the design process of a strategy implementation workshop.

The organization type may matter to the success of iterative prototyping. It may have helped this multiple case study that the company's product is design of diesel engines, so managers and employees taking part in the iterative prototyping of a workshop design were already accustomed to working with design processes, albeit product-related ones. Organizations with less affinity to design processes may be less favorably disposed to working with iterative prototyping in connection with strategy processes. The diesel engine company's strategy was loosely formulated and centered on broad objectives, and the business areas and their departments autonomously interpreted the strategy and planned actions that were evaluated by department managers and employees to support the strategy. An organization with a blueprint strategy that cascades quantified targets from top to bottom (Mintzberg, Ahlstrand and Lampel, 2005, p. 57) may be less suited for this kind of workshop design development.

Knowledge and understanding of strategy implementation can be improved by focusing on the transfer of concepts and their associated processes from the design realm to organizations. This study suggests that iterative prototyping offers promising possibilities for organizations seeking to augment alignment of problem solving and action planning in connection with strategy implementation through a resource-light endeavor such as a three hour workshop.

\section{References}

van Aaken, D. et al. (2013) 'Ausgestaltung und Erfolg von Strategieworkshops: Eine empirische Analyse', Zeitschrift für betriebswirtschaftliche Forschung, 65(November), pp. 588-616.

Austin, R. D. and Devin, L. (2003) Artful making: What managers need to know about how artists work. FT Press.

Balogun, J., Best, K. and Lê, J. (2015) 'Selling the Object of Strategy: How Frontline Workers Realize Strategy through their Daily Work', Organization Studies, 36(10), pp. 1285-1313. doi: 10.1177/0170840615590282.

Bamford, D. R. and Forrester, P. L. (2003) 'Managing planned and emergent change within an operations management environment', International Journal of Operations \& Production Management, 23(5), pp. 546-564. doi: 10.1108/01443570310471857.

Boje, D. M. (2001) 'Narrative Methods for Organizational and Communication Research', in Narrative Methods for Organizational and Communication Research. SAGE Publications, pp. 1-17.

Bourque, N. and Johnson, G. (2009) 'Strategy Workshops and "Away Days" as Ritual', in Hodgkinson, G. P. and Starbuck, W. H. (eds) The Oxford Handbook of Organizational Decision Making. Oxford Handbooks Online, pp. 1-16. doi: 10.1093/oxfordhb/9780199290468.003.0029.

Bürgi, P. T., Jacobs, C. D. and Roos, J. (2005) 'From Metaphor to Practice: In the Crafting of Strategy', Journal 
of Management Inquiry, 14(1), pp. 78-94. doi: 10.1177/1056492604270802.

Clarke, I., Kwon, W. and Wodak, R. (2012) 'A Context-sensitive Approach to Analysing Talk in Strategy Meetings', British Journal of Management, 23(4), pp. 455-473. doi: 10.1111/j.1467-8551.2011.00759.x.

Coghlan, D. (2011) 'Action Research: Exploring Perspectives on a Philosophy of Practical Knowing', The Academy of Management Annals, 5(1), pp. 53-87. doi: 10.1080/19416520.2011.571520.

Coghlan, D. and Shani, A. B. (Rami) (2005) 'Roles, politics, and ethics in action research design', Systemic Practice and Action Research, 18(6), pp. 533-546. doi: 10.1007/s11213-005-9465-3.

Coghlan, D. and Shani, A. B. (Rami) (2008) 'Insider action research: The dynamics of developing new capabilities', in Reason, P. and Bradbury, H. (eds) The SAGE Handbook of Action Research. 2nd edn. London: SAGE Publications Ltd, pp. 634-656. doi: http://dx.doi.org.esc-web.lib.cbs.dk/10.4135/9781848607934.n56.

Dow, S. P., Heddleston, K. and Klemmer, S. R. (2011) 'The Efficacy of Prototyping Under Time Constraints', Design Thinking. Springer Berlin Heidelberg, pp. 111-128. doi: 10.1007/978-3-642-13757-0_7.

Ericsson, K. A. et al. (eds) (2006) The Cambridge handbook of expertise and expert performance. Cambridge University Press.

Gherardi, S. and Perrotta, M. (2014) 'Between the hand and the head', Qualitative Research in Organizations and Management: An International Journal, 9(2), pp. 134-150. doi: doi:10.1108/QROM-06-2012-1079.

Healey, M. P. et al. (2015) 'Off to Plan or Out to Lunch? Relationships between Design Characteristics and Outcomes of Strategy Workshops', British Journal of Management, 26(3), pp. 507-528. doi: 10.1111/14678551.12038.

Hendry, J. and Seidl, D. (2003) 'The structure and significance of strategic episodes: social systems theory and the routine practices of strategic change', Journal of Management Studies, 40(1), pp. 175-196.

Hodgkinson, G. P. et al. (2006) 'The Role of Strategy Workshops in Strategy Development Processes: Formality, Communication, Co-ordination and Inclusion', Long Range Planning, 39(5), pp. 479-496. doi: 10.1016/j.Irp.2006.07.003.

Huang, H. B. (2010) 'What is good action research?: Why the resurgent interest?', Action Research, 8(1), pp. 93-109. doi: 10.1177/1476750310362435.

Jarzabkowski, P. and Seidl, D. (2008) 'The Role of Meetings in the Social Practice of Strategy', Organization Studies, 29(11), pp. 1391-1426. doi: 10.1177/0170840608096388.

Jarzabkowski, P. and Spee, A. P. (2009) 'Strategy-as-practice: A Review and Future Directions for the Field', International Journal of Management Reviews, 11(1), pp. 69-95. doi: 10.1111/j.1468-2370.2008.00250.x.

Johnson, G. et al. (2010) 'The Ritualization of Strategy Workshops', Organization Studies, 31(12), pp. 15891618. doi: 10.1177/0170840610376146.

Knott, P. (2008) 'Strategy tools: who really uses them?', Journal of Business Strategy, 29(5), pp. 26-31. doi: 10.1108/02756660810902297.

Kwon, W., Clarke, I. and Wodak, R. (2014) 'Micro-Level Discursive Strategies for Constructing Shared Views around Strategic Issues in Team Meetings', Journal of Management Studies, 51(2), pp. 265-290. doi: 10.1111/joms.12036.

Langley, A. et al. (2013) 'Process studies of change in organization and management: Unveiling temporality, activity, and flow', Academy of Management Journal, 56(1), pp. 1-13. doi: 10.5465/amj.2013.4001. 
Liu, F. and Maitlis, S. (2014) 'Emotional Dynamics and Strategizing Processes: A Study of Strategic Conversations in Top Team Meetings', Journal of Management Studies, 51(2), pp. 202-234. doi: 10.1111/j.1467-6486.2012.01087.x.

Maclntosh, R., MacLean, D. and Seidl, D. (2010) 'Unpacking the effectivity paradox of strategy workshops: do strategy workshops produce strategic change?', in Golsorkhi, D. (ed.) Cambridge Handbook of Strategy as Practice. Cambridge: Cambridge University Press, pp. 291-309.

Macpherson, A. and Antonacopoulou, E. (2013) 'Translating strategy into practice: the role of communities of practice', Journal of Strategy and Management, 6(3), pp. 265-285. doi: 10.1108/JSMA-11-2012-0061.

Mintzberg, H., Ahlstrand, B. and Lampel, J. (2005) Strategy Safari: A Guided Tour Through The Wilds of Strategic Mangament. Free Press.

Paroutis, S., Franco, L. A. and Papadopoulos, T. (2015) 'Visual Interactions with Strategy Tools: Producing Strategic Knowledge in Workshops', British Journal of Management, 26(S1), pp. S48-S66. doi: 10.1111/14678551.12081.

Pugh, J. and Bourgeois, L. J. (2011) '“Doing" strategy', Journal of Strategy and Management, 4(2), pp. 172-179. doi: 10.1108/17554251111128637.

Ranjbar, M. S., Shirazi, M. A. and Blooki, M. L. (2014) 'Interaction among intra- organizational factors effective in successful strategy execution: An analytical view', Journal of Strategy Management, 7(2), pp. 127-154. doi: 10.1108/JSMA-05-2013-0032.

Roos, J., Victor, B. and Statler, M. (2004) 'Playing Seriously with Strategy', Long Range Planning, 37(6), pp. 549-568. doi: 10.1016/j.Irp.2004.09.005.

Roth, J., Sandberg, R. and Svensson, C. (2011) 'The Dual Role of the Insider Action Researcher', in Adler, N., Shani, A. (Rami), and Styhre, A. (eds) Collaborative research in organizations. Thousand Oaks: SAGE, pp. 117134. doi: http://dx.doi.org/10.4135/9781412983679.

Salas, K. De and Huxley, C. (2014) 'Enhancing visualisation to communicate and execute strategy: Strategy-toProcess Maps', Journal of Strategy and Management, 7(2), pp. 109-126. doi: 10.1108/JSMA-10-2012-0055.

Schein, E. H. (2008) 'Clinical Inquiry/Research', in Reason, P. and Bradbury, H. (eds) The SAGE Handbook of Action Research. London: SAGE Publications Ltd, pp. 266-280. doi: 10.4135/9781848607934.d26.

Schrage, M. (2013) Serious play: How the world's best companies simulate to innovate. Harvard Business Press.

Schwarz, M. (2009) 'Strategy workshops facilitating and constraining strategy making', Journal of Strategy and Management, 2(3), pp. 277-287. doi: 10.1108/17554250910982507.

Seidl, D. and Guérard, S. (2015) 'Meetings and workshops as strategy practices', in Golsorkhi, D. et al. (eds) The Cambridge Handbook of Strategy as Practice. 2nd edn. Cambridge: Cambridge University Press, pp. 564581.

Shapiro, J. and Ross, V. (2002) 'Applications of narrative theory and therapy to the practice of family medicine', Family Medicine, 34(2), pp. 96-100.

Stavros, J., Cooperrider, D. and Kelley, D. L. (2003) 'Strategic inquiry appreciative intent: inspiration to SOAR, a new framework for strategic planning', Al Practitioner, November, pp. 10-17.

Welch, C. and Piekkari, R. (2011) 'Theorising from case studies: Towards a pluralist future for international business research', Journal of International Business Studies, 42(5), pp. 740-762. doi: 10.1057/jibs.2010.55. 
White, M. (2007) Maps of narrative practice. New York: WW Norton \& Company.

White, M. and Epston, D. (1990) Narrative means to therapeutic ends. New York: WW Norton \& Company.

Whittington, R. (2003) 'The work of strategizing and organizing: for a practice perspective', Strategic Organization, 1(1), pp. 117-125. doi: 10.1177/147612700311006.

Whittington, R. (2006) 'Completing the Practice Turn in Strategy Research', Organization Studies, 27(5), pp. 613-634. doi: 10.1177/0170840606064101.

Wodak, R., Kwon, W. and Clarke, I. (2011) '"Getting people on board": Discursive leadership for consensus building in team meetings', Discourse \& Society, 22(5), pp. 592-644. doi: 10.1177/0957926511405410. 